\title{
Selecting Critical Properties of Terpenes and Terpenoids through Group-Contribution Methods and Equations of State
}

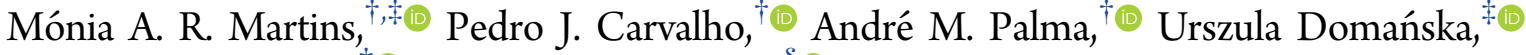 \\ João A. P. Coutinho, ${ }^{\dagger}$ and Simão P. Pinho*,\$® \\ ${ }^{\dagger}$ CICECO-Aveiro Institute of Materials, Department of Chemistry, University of Aveiro, Aveiro, 3810-193, Portugal \\ ${ }^{\star}$ Physical Chemistry Department, Warsaw University of Technology, Warsaw, 00-661, Poland

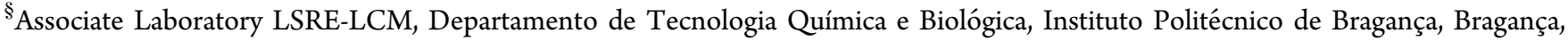 \\ 5301-857, Portugal
}

\section{Supporting Information}

ABSTRACT: The knowledge of critical properties is fundamental in engineering process calculations for the estimation of thermodynamic properties and phase equilibria. A literature survey shows a large number of methods for predicting critical properties of different classes of compounds, but no previous study is available to evaluate their suitability for terpenes and terpenoids. In this work, the critical properties of terpenes and terpenoids were first estimated using the groupcontribution methods of Joback, Constantinou and Gani, and Wilson and Jasperson. These were then used to calculate densities and vapor pressure through the equations of state Peng-Robinson (PR) and Soave-Redlich-Kwong (SRK) and then compared with the experimental values. On other hand, density and vapor pressure experimental data were used to estimate the critical properties directly by the same equations of state (EoSs), allowing a comparison between the two estimation procedures. For this purpose densities for 17 pure terpenes and terpenoids were here

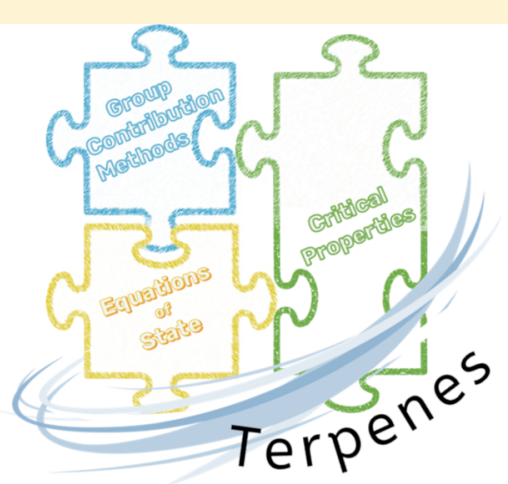
measured at atmospheric pressure in the temperature range $(278.15$ to 368.15$) \mathrm{K}$. Using the first approach, the best combination is the Joback's method with the Peng-Robinson EoS, despite the high relative deviations found for vapor pressure calculations and difficulties to predict density at low temperatures. Following the second approach, the set of critical properties and acentric factors estimated are able to adequately correlate the experimental data. Both equations show a similar capability to correlate the data with SRK EoS presenting a global \%ARD of 3.16 and 0.62 for vapor pressure and density, respectively; while the PR EoS presented 3.61 and 0.66 , for the same properties, both giving critical properties estimates also closer to those calculated by the Joback method, which is the recommended group-contribution method for this type of compounds.

\section{INTRODUCTION}

Terpenes, and their oxygenated forms called terpenoids, are the most diverse class of natural compounds with more than 55000 different structures reported. ${ }^{1,2}$ They represent the oldest known biomolecules and are components of volatile floral and fruit scents. Despite the diversity of their structures and function, all terpenes and terpenoids derive from the common 5-carbon building block, isoprene. ${ }^{3}$

Because of their exceptional importance, a result of their many biological roles in nature, these compounds have been widely used since the Egyptians. ${ }^{1}$ Many applications for human society developments are known in the areas of pharmaceutical, $^{4}$ food, ${ }^{3,5}$ and the cosmetic industries, ${ }^{6}$ which have been exploring these compounds for their multiple beneficial roles as medicines, flavor enhancers, and fragrances. ${ }^{1}$ Terpenes have also been studied with great interest because of their roles in the atmosphere, since the annual global emission of isoprene was estimated at 500 megatonnes.

Despite being widely used and investigated by researchers there is still an enormous lack of experimental thermodynamic properties for systems containing terpenes. Aqueous solubilities, vapor pressures, and octanol-water partition coefficients, required to assess environment fate and transport, and critical properties, used as the basis for the estimation of a large variety of thermodynamic, volumetric, and transport properties using the corresponding states principle are required.

Critical temperatures and pressures provide valuable information for the estimation of vapor pressures and are essential for the description of pure component and mixture behavior by equations of state $(\mathrm{EoS}){ }^{8}$ However, their experimental determination is complex, expensive, and in many cases impossible, since the large and strongly associating components usually decompose before the critical point. Thus, experimental data are usually only available for the smaller

Received: $\quad$ May 31, 2017

Revised: July 28, 2017

Accepted: August 10, 2017

Published: August 10, 2017 
molecules, and predictive methods must be used for the more complex substances. ${ }^{9-13}$

Considering terpenes, to the best of our knowledge, only the critical volume and temperature for limonene, $\alpha$-pinene, and 3carene have been published in the open literature, ${ }^{14}$ and the results are considerably uncertain since terpenes are unstable at their critical point. ${ }^{15}$ Moreover, Poling et al. ${ }^{16,17}$ presents the critical temperature of thymol and $\mathrm{L}(-)$-menthol and the critical temperature and pressure of $p$-cymene. As seen in the literature, when critical properties of terpenes are required, most authors use group contribution methods to estimate them. $^{18-20}$

Because of their practical and theoretical importance, the estimation of critical properties has attracted the interest of researchers and a wide variety of estimation methods are available in the open literature. Riedel ${ }^{21}$ and Lydersen ${ }^{22}$ were the first to develop group-contribution methods for critical properties estimation, followed by many others. ${ }^{9-11,23-33}$ Moreover, there are also publications related with the use of quantitative structure property relation (QSPR) correlations, and popular mathematical methods like neural networks. A broad overview of these methods together with a detailed discussion of their reliability have been published during the past years. ${ }^{17,34}$ In addition, some authors have evaluated the performance of models utilizing a large common set of experimental data. ${ }^{8}$

Owing to the scarcity of experimental critical data for terpenes, the use of group-contribution schemes seems to be the adequate approach to obtain quick and reliable estimations. Most of the techniques require only the molecular structure and, additionally, other properties such as the normal boiling point. ${ }^{17}$ The main issue is how the different estimated values compare and what is their performance in terms of volumetric properties or vapor pressure estimations through a cubic equation of state $(\mathrm{EoS})$.

If accurate critical properties can be found, their use in corresponding state methods, such as the Lee-Kesler generalized correlation $^{35}$ and cubic Equations of State, ${ }^{36-39}$ is useful for the prediction of thermodynamic properties and phase equilibria. These EoSs play an important role in chemical engineering design and nowadays, the Peng-Robinson (PR) ${ }^{39}$ and Soave-Redlich-Kwong (SRK) ${ }^{38}$ equations of state are the most widely used in process simulators such as Aspen-Plus or GPROMS. ${ }^{40}$ Several advantages of these EoSs are related to how they can accurately and easily represent the relationship between temperature, pressure, and compositions in binary and multicomponent systems, requiring only the critical properties and acentric factor as generalized parameters.

The aim of this work is to evaluate the best set of critical properties (critical temperature, critical pressure), and acentric factor, for terpenes and terpenoids to be used with the SoaveRedlich-Kwong $^{38}$ and Peng-Robinson ${ }^{39}$ equations of state. Two approaches were followed (Figure 1):

1. Apply the estimated critical properties using the group contribution methods developed by Joback, ${ }^{9}$ Constantinou and Gani, ${ }^{11}$ and Wilson and Jasperson, ${ }^{23}$ to calculate densities and vapor pressure through equations of state, and compare both experimental and calculated sets.

2. Use experimental densities and vapor pressures to estimate the critical properties by the same equations of state.

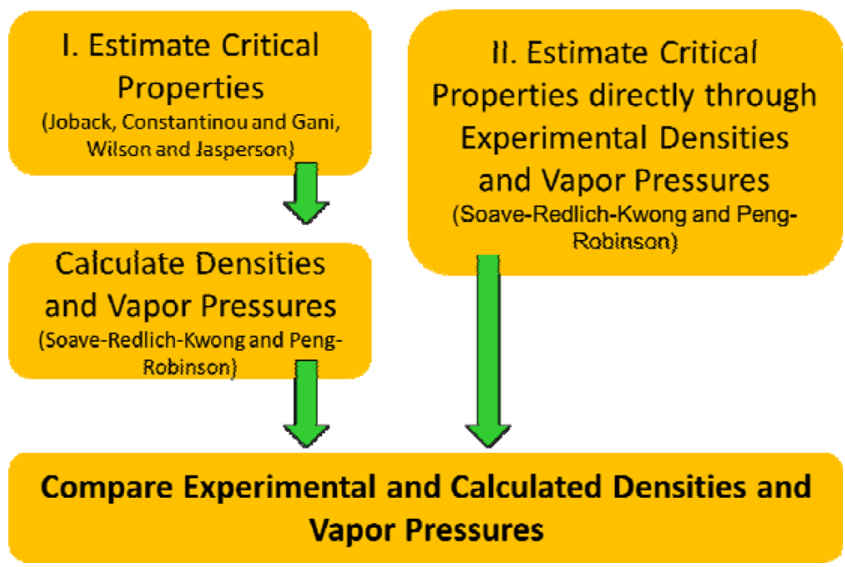

Figure 1. Schematic representation of the procedure followed in this work.

Density data were here measured experimentally at atmospheric pressure, while vapor pressure values were taken from the literature.

\section{EXPERIMENTAL SECTION}

2.1. Chemicals. Detailed information about the terpenes and terpenoids investigated in this work is presented in Table 1. Compounds were used without any further purification.

2.2. Density Measurements. Density measurements of the pure terpenes and terpenoids were carried out at atmospheric pressure and in the (278.15 to 368.15$) \mathrm{K}$ temperature range, using an Anton Paar DMA 4500 vibrating-tube densimeter (Graz, Austria). Two integrated $\mathrm{Pt}$ 100 platinum thermometers provided good precision of the internal control of temperature $( \pm 0.01 \mathrm{~K})$ and the densimeter includes an automatic correction for the viscosity of the sample. The apparatus is precise to within $\pm 1 \times 10^{-5} \mathrm{~g} \cdot \mathrm{cm}^{-3}$ and the overall uncertainty of the measurements was estimated to be better than $\pm 5 \times 10^{-5} \mathrm{~g} \cdot \mathrm{cm}^{-3}$. Additional details related with the equipment can be found elsewhere. ${ }^{42}$ The density of $(R)$ $(+)$-limonene and $p$-cymene was measured using an automated SVM 3000 Anton Paar rotational Stabinger viscometerdensimeter (temperature uncertainty: $\pm 0.02 \mathrm{~K}$; absolute density uncertainty: $\pm 5 \times 10^{-4} \mathrm{~g} \cdot \mathrm{cm}^{-3}$ ) at atmospheric pressure and in the (278.15 to 368.15$) \mathrm{K}$ temperature range.

\section{MODELS}

3.1. Critical Properties. The following sections will briefly describe the methods used in this work to estimate the critical temperature, $T_{\mathcal{C}}$ and the critical pressure, $P_{\mathcal{c}}$ of terpenes and terpenoids, namely Joback $(1984 ; 1987), 9,29$ Constantinou and Gani (1994), ${ }^{11}$ and Wilson and Jasperson (1996). ${ }^{23}$

3.1.1. Joback Method. Joback ${ }^{9,29}$ proposed a groupcontribution method based on the Lydersen's group-contribution scheme, ${ }^{22}$ adding new functional groups, and establishing new parameter values. In this method no interactions between groups is assumed and the elemental contributions are mainly determined by the bonds within and among small groups of atoms. Table S1 of Supporting Information presents the structural groups and their respective contributions for each property estimated in this work. For $T_{c}$ a value of the normal boiling point, $T_{b}$, is needed (Table 1 ).

3.1.2. Constantinou and Gani (CG) Method. In 1994, Constantinou and $\mathrm{Gani}^{11}$ developed an advanced group- 
Table 1. Names, Structures, Supplier, Molar Mass $(M)$, Boiling Points ${ }^{a}\left(T_{\mathrm{BP}}\right)$ and Mass Fraction Purities (Declared by the Supplier) Of the Terpenes and Terpenoids Used

\begin{tabular}{|c|c|c|c|c|c|}
\hline Chemical & Supplier & CAS & $M / \mathrm{g} \cdot \mathrm{mol}^{-1}$ & $T_{\mathrm{BP}}^{a} / \mathrm{K}$ & wt \% \\
\hline \multicolumn{6}{|c|}{ Terpenes } \\
\hline$(\mathrm{R})-(+)$-limonene & Aldrich & $5989-27-5$ & 136.23 & 449.65 & 97 \\
\hline$\alpha$-pinene & Sigma-aldrich & $80-56-8$ & 136.23 & 429.29 & 98 \\
\hline$\beta$-pinene & Sigma-aldrich & $18172-67-3$ & 136.23 & 439.19 & 99 \\
\hline$p$-cymene & Aldrich & $99-87-6$ & 134.22 & 450.28 & 99 \\
\hline \multicolumn{6}{|c|}{ Terpenoids } \\
\hline$(-)$-menthone & Fluka & $14073-97-3$ & 154.25 & 483.15 & $\geq 99$ \\
\hline$(1 \mathrm{R})-(-)$-fenchone & Aldrich & $7787-20-4$ & 152.23 & 466.15 & $\geq 98$ \\
\hline (S)-(+)-carvone & Merck & $218-827-2$ & 150.22 & 504.15 & 96 \\
\hline Carvacrol & SAFC & $499-75-2$ & 150.22 & 510.15 & 99 \\
\hline Eucalyptol & Aldrich & $470-82-6$ & 154.25 & 449.55 & 99 \\
\hline DL-citronellol & Sigma & $106-22-9$ & 156.26 & 496.40 & $\approx 95$ \\
\hline Eugenol & Aldrich & $97-53-0$ & 164.20 & 526.35 & 99 \\
\hline Geraniol & Sigma-aldrich & $106-24-1$ & 154.25 & $503.15^{a}$ & 98 \\
\hline$(-)$-isopulegol & SAFC & $89-79-2$ & 154.25 & 480.98 & $\geq 98$ \\
\hline Linalool & Aldrich & $78-70-6$ & 154.25 & 470.15 & 97 \\
\hline $\mathrm{L}(-)$-menthol & Acros & $2216-51-5$ & 156.26 & 487.40 & 99.7 \\
\hline Thymol & Sigma & $89-83-8$ & 150.22 & 505.65 & $\geq 99.5$ \\
\hline$\alpha$-pinene oxide & Aldrich & $1686-14-2$ & 152.23 & 489.51 & 97 \\
\hline
\end{tabular}

${ }^{a_{\text {Taken }} \text { from Yaws. }}{ }^{41}$

contribution method based on UNIFAC and in a two level estimation scheme. The basic level has contributions from firstorder functional groups and the next level has second-order groups, which provide further information about the molecular structure of the compound. Table S2 of the Supporting Information presents the set of groups and the respective contributions for each property used in this work.

3.1.3. Wilson and Jasperson Method. The method reported by Wilson and Jasperson $(\mathrm{WJ})^{23}$ uses the nature of the atoms involved to determine the elemental contributions. It can be applied to both organic and inorganic species. The first order method uses atomic contributions along with boiling point and number of rings, while the second order method also includes group contributions. Values of the contributions used in this work are given in Table S3 of the Supporting Information.
3.2. Acentric Factor. Along with the critical properties, a commonly used pure component constant for property estimation is the acentric factor, $\omega$. According to Poling et al., ${ }^{17}$ the most accurate technique to estimate the acentric factor is to use the critical constants.

3.3. Equations of State (EoSs). EoSs are used to relate temperature, pressure, and volume, the macroscopically measurable properties in a system. In this work, SoaveRedlich-Kwong $^{38}$ and the Peng-Robinson ${ }^{39}$ EoSs were selected.

Along this work, the accuracy of the estimations was evaluated by using the statistical parameter average relative deviation (\%ARD):

$$
\% \text { ARD }=\frac{1}{N} \sum_{i=1}^{N}\left|\frac{X^{\text {exp }}-X^{\text {calc }}}{X^{\text {calc }}}\right| 100
$$


where $X^{\text {exp }}$ and $X^{\text {cal }}$ refer to the experimental and calculated property, respectively, and $N$ is the number of data points.

\section{RESULTS AND DISCUSSION}

4.1. Density Measurements. Density measurements for the terpenes and terpenoids here studied were carried out in the temperature range ( 278.15 to 368.15 ) $\mathrm{K}$ and at atmospheric pressure. Results are reported in the Table S4 of the Supporting Information and depicted in Figure 2. As expected the density
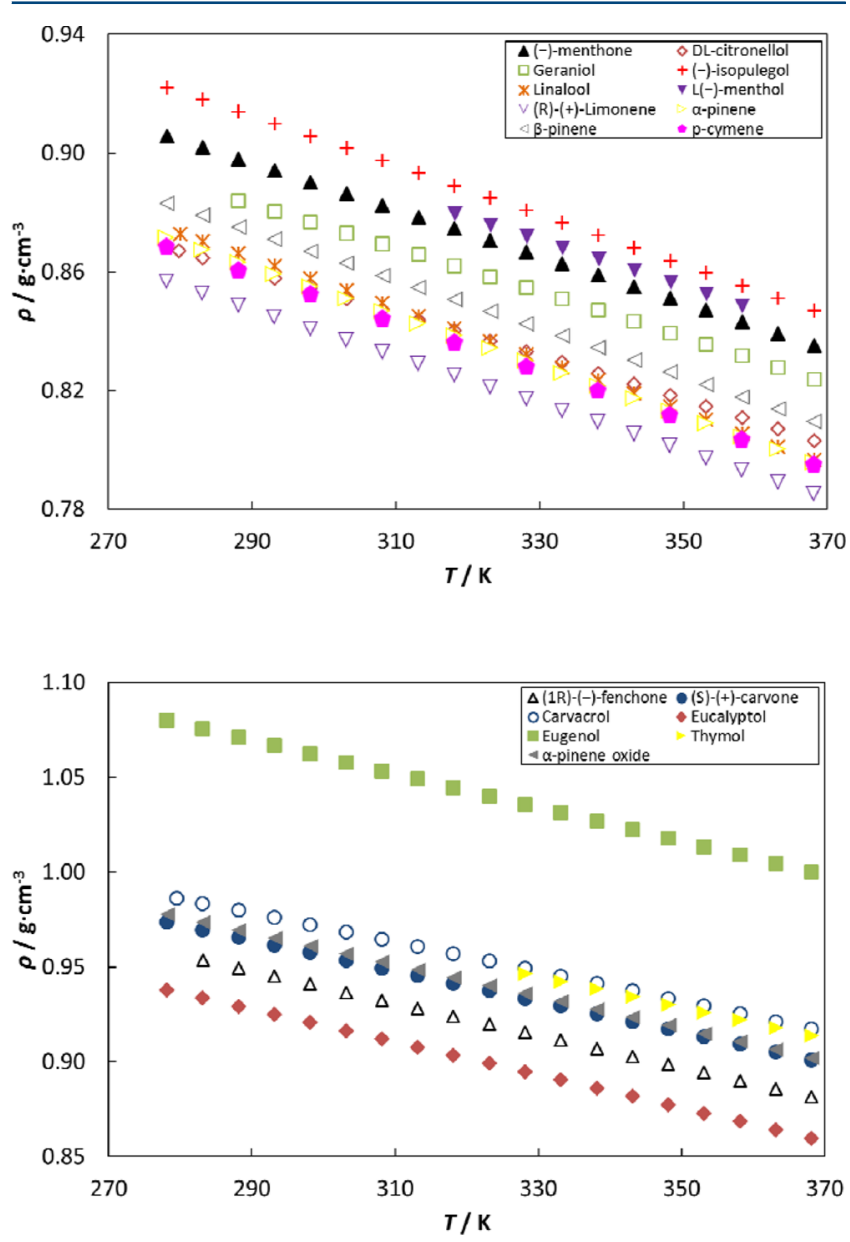

Figure 2. Density, $\rho$, of pure terpenes and terpenoids as a function of temperature and at $0.1 \mathrm{MPa}$.

decreases linearly with increasing temperature. In the studied temperature range, eugenol is the compound presenting higher density, while $(R)-(+)$-limonene is the less dense compound. The phenylpropene eugenol is the only compound with densities higher than $1 \mathrm{~g} \cdot \mathrm{cm}^{-3}$ throughout the temperature range studied.

Although new density data of terpenes and terpenoids were measured in this work, it should be remarked that many other authors already reported this property for the same terpenes at different temperatures. However, no data were found for carvacrol, thymol, or $\alpha$-pinene oxide. The maximum relative deviations between the experimental values measured in this work and those reported in the literature are presented in Figure 3 and Table 2. As can be seen a good agreement is found for all compounds, with an average relative deviation of $0.14 \%$ and a maximum relative deviation of $0.62 \%$.

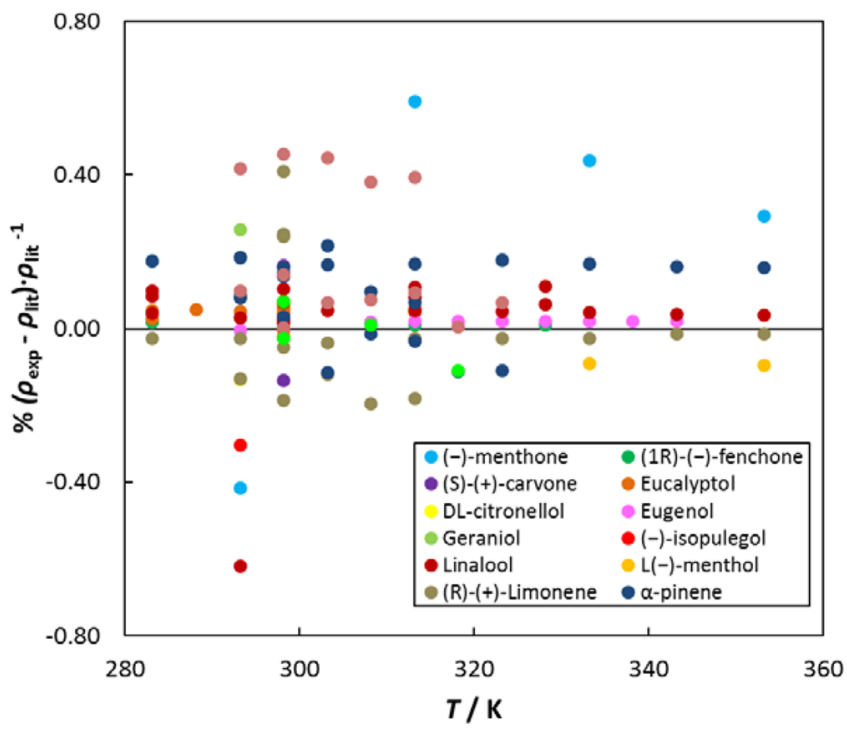

Figure 3. Percentage relative deviations between density data determined here and those from literature (references in Table 2).

4.2. Critical Properties and Acentric Factor. I. Estimation of Critical Properties Using Group Contribution Methods and EoS. Following the approach described before, the critical properties of terpenes and terpenoids were estimated using the group contribution methods of Joback, ${ }^{9}$ Constantinou and Gani (CG), ${ }^{11}$ and Wilson and Jasperson $(\mathrm{WJ}){ }^{23}$ Results are shown in Table 3, alongside with the acentric factor, and a structural analysis is presented in Figure 4. Joback and CG methods cannot be applied to all the substances studied due to the absence of some groups.

Figure 4 shows a comparison between the critical properties estimated by the various methods. Some discrepancies between the results, possibly related with limitations associated with each method, some which were previously observed by other authors, $^{63}$ are identified. When the different methods are compared, acentric factors present higher variability than the critical properties, especially for aromatic monocyclic terpenes, with eugenol being a patent outlier. Regarding critical temperatures and pressures, differences are more noticeable for $(S)-(+)$-carvone and (-)-menthone. Noncyclic compounds have the lowest dispersion indicating that linear compounds are more easily described by the group contribution methods available. Critical pressures from Joback method are usually larger than those by the CG and WJ methods, while generally it is clear that the Joback and WJ methods present, for this set of compounds, closer results among the methods tested.

In his initial study, Joback employed only 41 molecular groups, which oversimplifies the molecular structure, thus making several types of isomers indistinguishable. Overall this is insufficient to capture the structural effects of organic molecules and is the main reason for some inaccuracy of the method. Moreover, in CG method a group appearing in an aliphatic ring is considered equivalent to its nonring counterpart. These groups cannot distinguish between special configurations such as multiple groups located close to each other and resonance structures. The WJ method requires additional information apart from structure and boiling point, what makes it more complex and sensitive to errors.

As pointed out, all group contribution methods present weaknesses. Therefore, to choose the best model to represent 
Table 2. Maximum Relative Deviations between the Experimental Values Measured in This Work and Those Reported in the Literature $^{a}$

\begin{tabular}{|c|c|c|c|}
\hline substance & maximum relative deviation (\%) & substance & maximum relative deviation (\%) \\
\hline (-)-menthone & $0.59^{43}$ & (-)-isopulegol & $0.30^{44}$ \\
\hline$(1 R)-(-)$-fenchone & $0.02,,^{45} 0.04,^{46} 0.01^{47}$ & linalool & $0.62,^{44} 0.11,^{20} 0.07,^{48} 0.02,^{49} 0.03,^{50} 0.05,^{51} 0.09^{52}$ \\
\hline$(S)-(+)$-carvone & $0.14,^{48} 0.16^{53}$ & $\mathrm{~L}(-)$-menthol & $0.10^{43}$ \\
\hline eucalyptol & $0.05,,^{54} 0.05,,^{55} 0.01,,^{56} 0.04,,^{57} 0.06,,^{50} 0.06^{58}$ & $(R)-(+)$-limonene & $0.25,,^{46} 0.20,{ }^{59} 0.24,^{48} 0.41,,^{49} 0.05^{51}$ \\
\hline DL-citronellol & $0.13^{44}$ & $\alpha$-pinene & $0.22,^{59} 0.19,^{51} 0.14,^{58} 0.11^{60}$ \\
\hline eugenol & $0.02,^{61} 0.01^{62}$ & $\beta$-pinene & $0.46,^{59} 0.02,{ }^{48} 0.01,,^{58} 0.14^{60}$ \\
\hline geraniol & $0.26^{44}$ & $p$-cymene & $0.03,^{58} 0.11^{60}$ \\
\hline
\end{tabular}

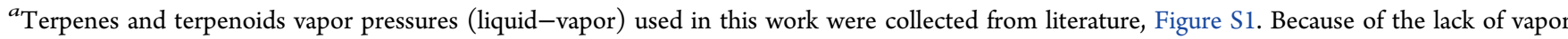
pressure data of $\alpha$-pinene oxide, this compound was not considered in the following calculations.

Table 3. Critical Properties of Terpenes and Terpenoids Estimated with Different Contribution Methods

\begin{tabular}{|c|c|c|c|c|c|c|c|c|c|}
\hline & \multicolumn{3}{|c|}{$T_{c} / \mathrm{K}$} & \multicolumn{3}{|c|}{$P_{\mathrm{c}} / \mathrm{MPa}$} & \multicolumn{3}{|c|}{$\omega$} \\
\hline & Joback & CG & WJ & Joback & CG & WJ & Joback & CG & WJ \\
\hline (-)-menthone & 689.70 & 679.35 & 727.31 & 2.60 & 2.43 & 2.79 & 0.412 & 0.459 & 0.218 \\
\hline (1R)-(-)-fenchone & 679.18 & $a$ & 707.95 & 3.08 & $a$ & 2.81 & 0.388 & $a$ & 0.189 \\
\hline$(S)-(+)$-carvone & $a$ & 688.74 & 772.76 & $a$ & 2.40 & 3.16 & $a$ & 0.619 & 0.198 \\
\hline carvacrol & 722.20 & 734.81 & 716.34 & 3.44 & 2.85 & 2.93 & 0.581 & 0.408 & 0.553 \\
\hline eucalyptol & 661.05 & $a$ & 635.70 & 3.02 & $a$ & 2.44 & 0.339 & $a$ & 0.432 \\
\hline DL-citronellol & 657.87 & 675.94 & 672.09 & 2.45 & 2.19 & 2.30 & 0.848 & 0.591 & 0.657 \\
\hline eugenol & 735.58 & 772.46 & 733.37 & 3.58 & 2.71 & 2.93 & 0.676 & 0.306 & 0.599 \\
\hline geraniol & 671.67 & 682.12 & 684.75 & 2.57 & 2.18 & 2.42 & 0.820 & 0.617 & 0.648 \\
\hline isopulegol & 656.76 & 682.75 & 667.43 & 2.77 & 2.36 & 2.56 & 0.698 & 0.398 & 0.558 \\
\hline linalool & 633.30 & 650.00 & 639.84 & 2.58 & 2.16 & 2.26 & 0.755 & 0.494 & 0.612 \\
\hline $\mathrm{L}(-)$-menthol & 661.63 & 679.32 & 672.52 & 2.66 & 2.38 & 2.50 & 0.716 & 0.496 & 0.580 \\
\hline$R$-(+)-Limonene & $a$ & 639.85 & 649.99 & $a$ & 2.41 & 2.72 & $a$ & 0.394 & 0.373 \\
\hline Thymol & 715.83 & 734.76 & 710.02 & 3.44 & 2.84 & 2.91 & 0.581 & 0.367 & 0.549 \\
\hline$\alpha$-pinene & $a$ & 657.01 & 620.56 & $a$ & 3.37 & 2.60 & $a$ & 0.224 & 0.354 \\
\hline$\beta$-pinene & $a$ & 651.26 & 634.87 & $a$ & 3.22 & 2.66 & $a$ & 0.329 & 0.363 \\
\hline$p$-cymene & 656.89 & 664.29 & 655.59 & 2.91 & 2.47 & 2.84 & 0.359 & 0.249 & 0.358 \\
\hline
\end{tabular}

${ }^{a_{T}}$ The GC method cannot be applied due to the absence of some groups.

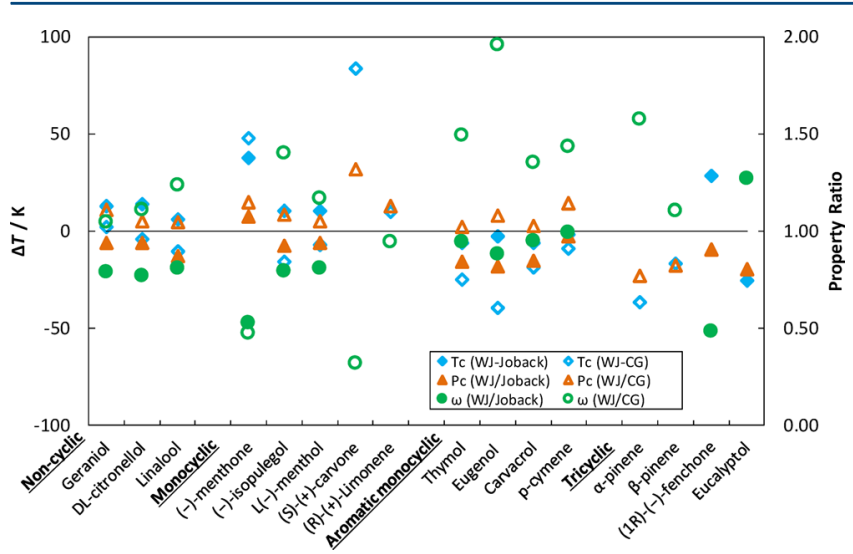

Figure 4. SRK-PR temperature difference $(\Delta T / K)$ and critical pressure and acentric factor ratio for the different contribution methods and compounds studied.

terpenes and terpenoids, the estimated sets of Table 3 were used to calculate densities and vapor pressures through the Soave-Redlich-Kwong and Peng-Robinson EoSs. The calculated values were compared with the experimental, and a global summary is displayed in Figure 5. Individual \%ARD values for each substance studied are presented in Table S5 of the Supporting Information.

Globally, the PR EoS presents better results than the SRK EoS. Regarding the group-contribution methods, for both

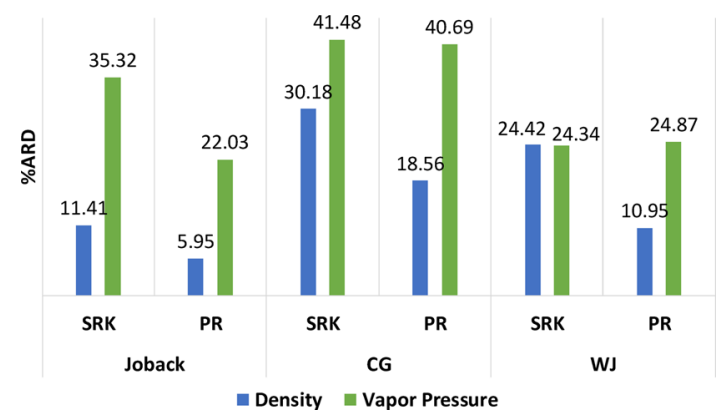

Figure 5. Global average relative deviation between the experimental and the predicted densities and vapor pressures, calculated using the PR and SRK EoS, with critical properties estimated by Joback, CG, and WJ methods.

properties, the smaller error was obtained with Joback. It is important to emphasize that the error obtained for vapor pressures is much higher than that for density, but the change of vapor pressure with temperature is far more pronounced and hard to describe in broader temperature ranges than the change in density.

So far the best combination found is the PR EoS with the Joback method. Thus, in order to further investigate the results obtained, calculated and experimental densities and vapor pressures, for some terpenes and terpenoids presenting consistent data, are depicted in Figure S2 and S3 of the 
Table 4. Critical Properties and Acentric Factor of Terpenes Estimated According to Approach II

\begin{tabular}{|c|c|c|c|c|c|c|}
\hline & \multicolumn{3}{|c|}{ SRK } & \multicolumn{3}{|c|}{ PR } \\
\hline & $T_{\mathrm{c}} / \mathrm{K}$ & $P_{\mathrm{c}} / \mathrm{MPa}$ & $\omega$ & $T_{\mathrm{c}} / \mathrm{K}$ & $P_{\mathrm{c}} / \mathrm{MPa}$ & $\omega$ \\
\hline (-)-menthone & 702.09 & 3.16 & 0.391 & 684.83 & 2.75 & 0.453 \\
\hline (1R)-(-)-fenchone & 671.30 & 3.36 & 0.403 & 675.00 & 3.02 & 0.403 \\
\hline$(S)-(+)$-carvone & 743.14 & 3.65 & 0.389 & 724.76 & 3.17 & 0.452 \\
\hline carvacrol & 744.38 & 3.69 & 0.479 & 727.07 & 3.20 & 0.542 \\
\hline eucalyptol & 643.72 & 3.10 & 0.398 & 636.37 & 2.75 & 0.432 \\
\hline DL-citronellol & 698.11 & 2.94 & 0.650 & 699.27 & 2.64 & 0.651 \\
\hline eugenol & 771.00 & 3.87 & 0.477 & 780.03 & 3.55 & 0.470 \\
\hline geraniol & 679.01 & 3.02 & 0.770 & 677.01 & 2.66 & 0.782 \\
\hline isopulegol & 690.01 & 3.22 & 0.490 & 689.05 & 2.86 & 0.500 \\
\hline linalool & 624.38 & 2.74 & 0.751 & 615.43 & 2.41 & 0.803 \\
\hline $\mathrm{L}(-)$-menthol & 659.80 & 2.94 & 0.713 & 647.03 & 2.56 & 0.779 \\
\hline$R$-(+)-Limonene & 655.51 & 3.27 & 0.385 & 655.50 & 2.93 & 0.395 \\
\hline thymol & 713.60 & 3.57 & 0.576 & 699.92 & 3.12 & 0.634 \\
\hline$\alpha$-pinene & 629.57 & 3.23 & 0.338 & 615.39 & 2.83 & 0.392 \\
\hline$\beta$-pinene & 642.53 & 3.34 & 0.345 & 635.97 & 2.95 & 0.372 \\
\hline$p$-cymene & 673.01 & 3.44 & 0.311 & 656.06 & 2.99 & 0.367 \\
\hline
\end{tabular}

Supporting Information, respectively. In general, the approach is able to establish a ranking for the magnitude of the density and vapor pressure values of the different terpenes, in conformity to the experimental observed rank, and a correct temperature trend for vapor pressures (Figure S3 of the Supporting Information). However, concerning the densities at low temperatures the correct temperature dependency is not always obtained showing that this cubic EoS should be used with precaution to estimate densities of liquids. Both EoS combined with the three group contribution methods here studied led to incorrect temperature dependency descriptions of the terpenes isopulegol, (-)-menthone, $(S)-(+)$-carvone, carvacrol, DL-citronellol, eugenol, geraniol, and linalool. Moreover, with the use of the SRK EoS, the experimental densities are always higher than the calculated values, while the calculated vapor pressures are in general higher than the experimental values. The same is observed using the EoS PR, excepting when using the critical properties estimated by the Joback method, for which the calculated densities are often higher than the experimental ones. The use of a constant volume translation could reduce the differences between the experimental and calculated liquid densities. ${ }^{64,65}$ However, this approach was not followed as the main goal here is to compare the group-contribution methods.

II. Estimation of Critical Properties Using Experimental Data and EoS. In the second approach proposed, experimental densities and vapor pressures were used to estimate the critical properties and the acentric factor directly by Soave-RedlichKwong and Peng-Robinson EoSs (Table 4). The critical properties obtained in the previous section were used as initial estimates, and the calculations were performed until the minimum error between experimental and estimated data was obtained (eq 1). The values of the estimated critical properties are generally in the same range to those estimated by group contributions methods.

In Figure 6 the critical SRK-PR temperature difference and critical pressure and acentric factor property ratio between the two EoSs applied is displayed. While critical pressures and temperatures are usually higher in the SRK equation than in the PR equation, acentric factors are almost always lower.

Individual \%ARD between the calculated and experimental densities and vapor pressures using SRK and PR EoSs are

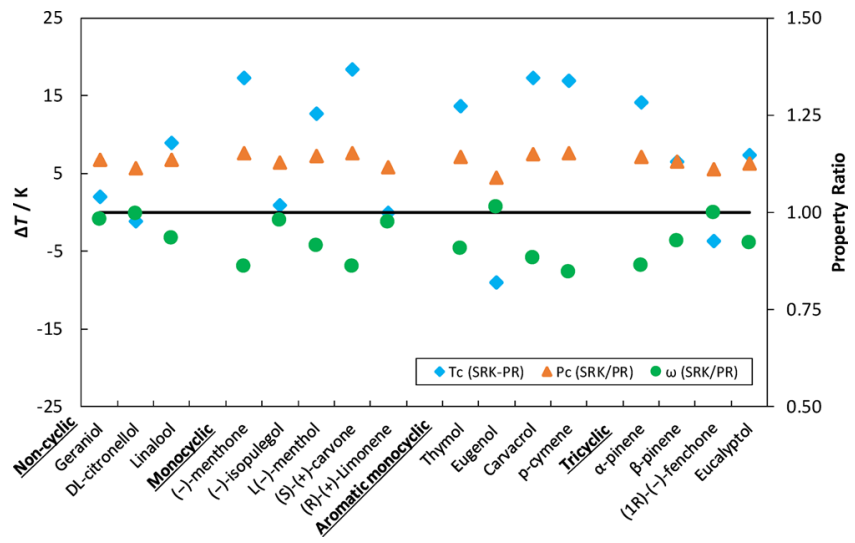

Figure 6. SRK-PR temperature difference $(\Delta T / K)$ and critical pressure and acentric factor ratio between Soave-Redlich-Kwong and Peng-Robinson EoSs for the compounds studied.

presented in Figure 7. Globally both equations show a similar correlation capability, with the SRK EoS presenting an \%ARD of 3.16 and $0.62 \%$ for vapor pressure and density, respectively; while the Peng-Robinson EoS presented 3.61 and $0.66 \%$, for the same properties.

The vapor pressure of DL-citronellol, geraniol, (-)-isopulegol, and $p$-cymene show higher \%ARD values. Table S6 shows that there is a decrease followed by an increase in the \%ARD with the temperature, indicating an intersection of the series. For $p$-cymene the \%ARD are randomly distributed with temperature. These are compounds with very low vapor pressures or compounds for which data are available in a larger temperature range. This somehow stresses the difficulty of measuring vapor pressure and the need of new experimental data in this field.

Figures S4 and S5 of the Supporting Information show a comparison between calculated and experimental densities and vapor pressures, for some terpenes and using the PengRobinson EoS. Concerning vapor pressure, this second approach is able to establish a ranking for the magnitude of values in conformity to the experimental observed rank, and a correct temperature trend, while for density an important 

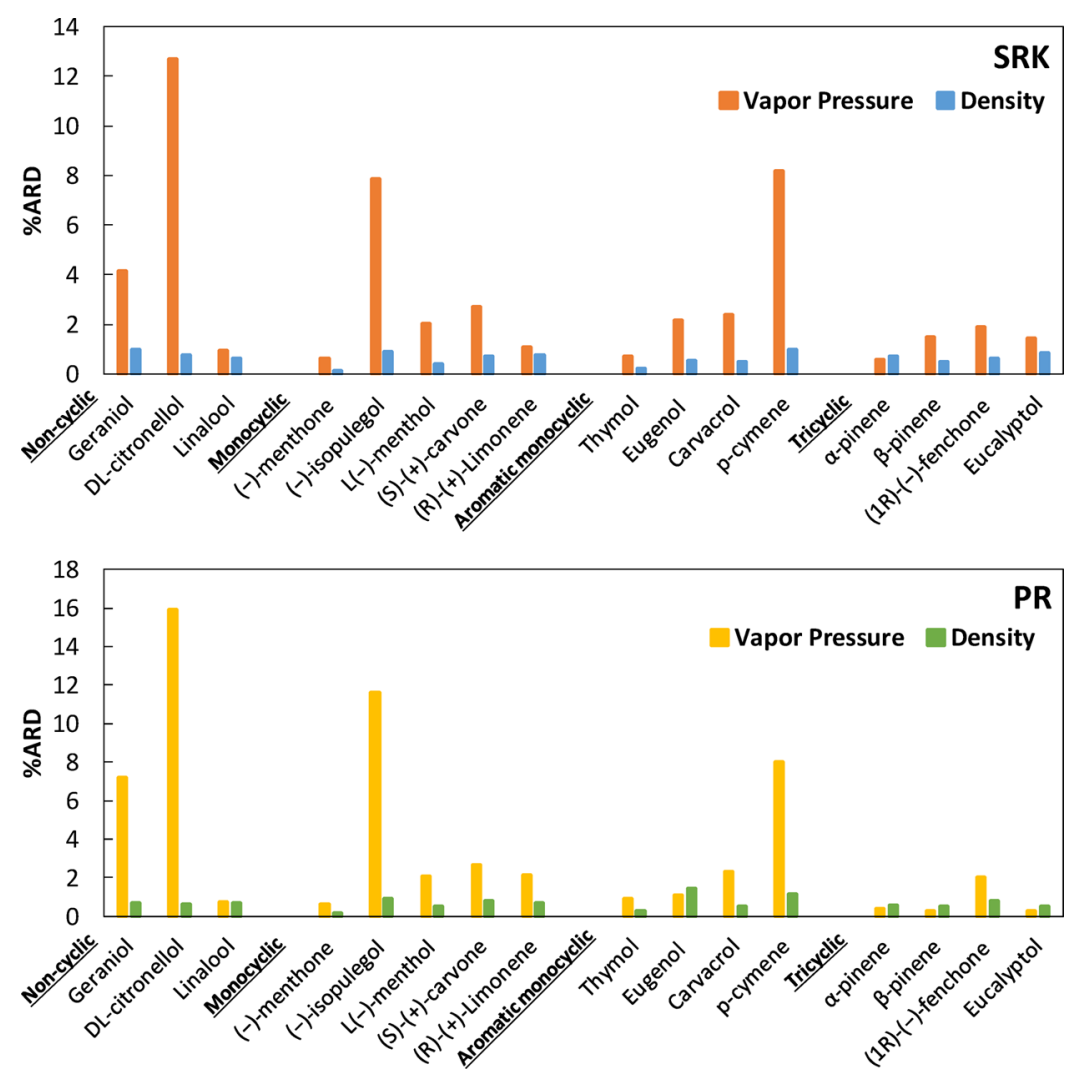

Figure 7. Average relative deviation between the experimental and the predicted densities and vapor pressures, calculated using the SRK and the PR, with critical properties estimated by the same EoS.

improvement is observed when compared with results shown before.

Methods Comparison. Comparing the critical properties and the acentric factor obtained by the group contribution methods and the EoS (Table 5) shows that the differences

Table 5. Critical Properties and Acentric Mean Absolute Error between Those Calculated by Group Contribution Methods and Those Estimated by the SRK and PR EoS

\begin{tabular}{llrr} 
& & PR & SRK \\
$T_{\mathrm{c}} / \mathrm{K}$ & Joback & 17.61 & 17.09 \\
& CG & 19.58 & 17.68 \\
& WJ & 19.39 & 18.18 \\
$P_{\mathrm{c}} / \mathrm{MPa}$ & Joback & 0.15 & 0.33 \\
& CG & 0.45 & 0.74 \\
$\omega$ & WJ & 0.23 & 0.61 \\
& Joback & 0.08 & 0.08 \\
& CG & 0.16 & 0.12 \\
& WJ & 0.10 & 0.09 \\
\hline
\end{tabular}

between critical temperatures are minor. The absolute error obtained for critical pressure shows higher deviations between the contribution methods and the EoS SRK. The opposite is verified for acentric factors; however, the effect is less pronounced.

4.3. Literature Analysis. For terpenes and terpenoids, experimental critical data are very rarely available, as only one work was found in the open literature. ${ }^{14}$ Additionally, Poling et al. $^{16,17}$ display the critical temperature of thymol and $\mathrm{L}(-)$ menthol and the critical temperature and pressure of $p$-cymene. The reason for this is that high molecular weight and strongly associating components readily decompose before the critical point is reached. This makes experimental measurements rather difficult and experimental errors very considerable. Table 6 presents, however, a comparison of critical temperatures estimated by the methods studied in this work, with the few experimental results, and some of the estimated values found in the literature for the same compounds. Poling et al. ${ }^{17}$ also presents the critical pressure for $p$-cymene $(2.8 \mathrm{MPa})$ that is in the same order of the critical pressures proposed in this work and pretty close to the values given by the Joback and WJ GC methods.

Within this very limited set of experimental values, and taking into account the decomposition problem of this class of compounds, any further analyses are premature. Regarding the estimated literature values, these are included in order to show the high variance of the critical properties values proposed in the literature, which establishes the importance of finding rational recommended values for the critical properties of terpenes and terpenoids

4.4. Validation. To validate the proposed sets of critical properties, these were used to describe the vapor-liquid equilibria (VLE) of mixtures of terpenes or mixtures of terpenes with supercritical $\mathrm{CO}_{2}$, using both equations of state SRK and PR. To perform these studies only a binary interaction parameter is estimated from the experimental data available.

Table 7 shows the average relative deviation found when correlating the experimental equilibrium temperatures reported by Nadais and Bernardo-Gil ${ }^{67}$ on the VLE of $\alpha$-pinene $+s(-)$ limonene at different pressures, while an example of the fitting is displayed in Figure 8. Results show that the pure components parameters here proposed guarantee a very satisfactory fit of the VLE of mixtures of terpenes. 
Table 6. Comparison of Estimated and Experimental Critical Temperatures

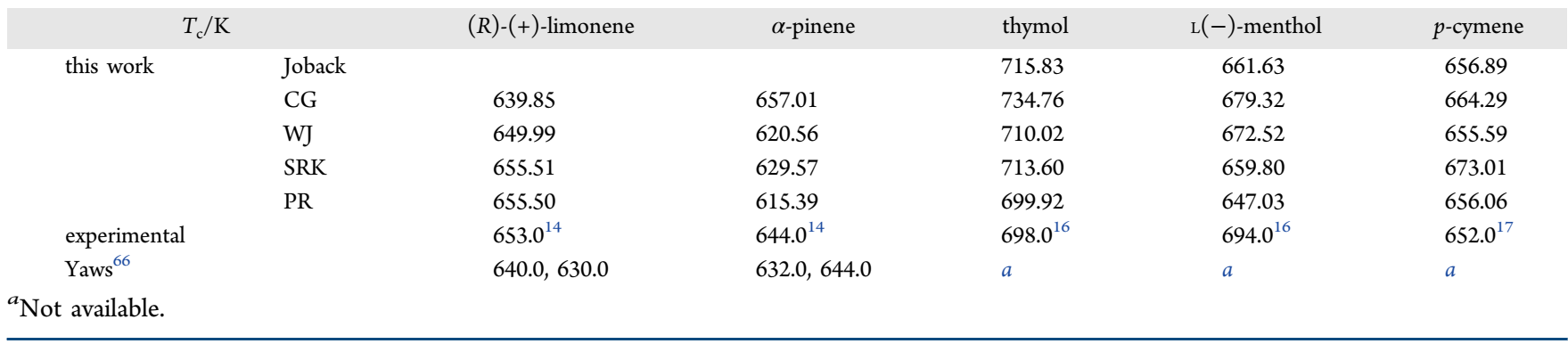

Table 7. Average Relative Deviation between the Experimental ${ }^{67}$ and the Predicted Temperatures of the VLE of the System $\alpha$ Pinene $+s(-)$-Limonene, Calculated Using the SRK and the PR Equations of State, with the Different Sets of Critical Properties (CPs). $k_{\mathrm{ij}}$ Refers to a Binary Interaction Parameter for the Energy of the Cubic Equation

\begin{tabular}{|c|c|c|c|c|c|c|c|c|}
\hline \multirow[b]{2}{*}{$\mathrm{CP}$} & \multicolumn{4}{|c|}{ SRK } & \multicolumn{4}{|c|}{ PR } \\
\hline & SRK & PR & WJ & CG & SRK & PR & WJ & CG \\
\hline \multirow[t]{2}{*}{$k_{i j}$} & -0.016 & -0.042 & -0.015 & -0.022 & -0.045 & -0.019 & -0.017 & -0.026 \\
\hline & \multicolumn{8}{|c|}{$40 \mathrm{kPa}$} \\
\hline \multirow[t]{2}{*}{$\% A R D$} & 0.238 & 0.321 & 0.206 & 0.278 & 0.311 & 0.324 & 0.241 & 0.353 \\
\hline & \multicolumn{8}{|c|}{$66.7 \mathrm{kPa}$} \\
\hline \multirow[t]{2}{*}{$\% A R D$} & 0.320 & 0.309 & 0.237 & 0.228 & 0.359 & 0.330 & 0.240 & 0.224 \\
\hline & \multicolumn{8}{|c|}{$101.3 \mathrm{kPa}$} \\
\hline$\% A R D$ & 0.366 & 0.353 & 0.135 & 0.222 & 0.383 & 0.341 & 0.160 & 0.240 \\
\hline average & 0.300 & 0.327 & 0.195 & 0.247 & 0.346 & 0.331 & 0.217 & 0.281 \\
\hline
\end{tabular}

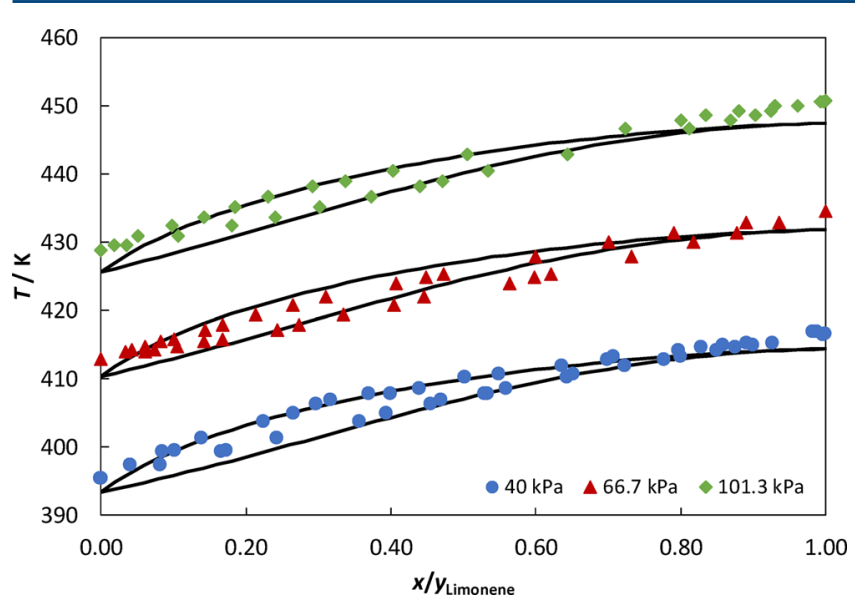

Figure 8. Experimental ${ }^{67}$ (points) and calculated (lines) vapor-liquid equilibrium of $\alpha$-pinene $+s(-)$-limonene at different pressures. Lines were calculated using the SRK EoS, and the critical properties were obtained by the same EoS through methodology II.

Another test was performed using the solubility data of supercritical $\mathrm{CO}_{2}$ in limonene and/or linalool measured by Vieira de Melo et al., ${ }^{68}$ that was computed using the critical properties estimated by methodology II and the SRK and PR
EoSs. Additionally, since Joback is the suggested GC method for terpenes and terpenoids (methodology I), the critical properties obtained by this method for linalool were used to perform the same calculations. The average relative deviation between the experimental and the calculated pressures is presented in Table 8 . As can be observed at least for the binary systems the calculations are in very good agreement with the experimental data. It also shows that replacing critical properties estimated from pure component vapor pressure and density data, to those calculated by Joback method, maintains the quality of the fit, strongly supporting the use of the Joback method for this type of compounds.

\section{CONCLUSIONS}

In this work three group-contribution methods for the estimation of critical properties were evaluated for terpenes and terpenoids. As expected, the variance between the results is high and therefore, their suitability is tested through cubic equations of state, calculating densities and vapor pressure, and comparing with experimental data. Results indicate that the best combination is the Joback method and the PengRobinson EoS. Vapor pressure calculations globally showed higher average relative deviations between the predicted and the experimental values when compared to density predictions.

Table 8. ARD between the Experimental ${ }^{68}$ and the Predicted Pressure for the VLE of the System $\mathrm{CO}_{2}+\mathrm{Linalool}_{\text {and }} /$ or Limonene, Calculated Using the Critical Properties Obtained by Methodology II and the Joback GC Method, at 323.15 K. The Binary Interaction for the Energy of the Cubic Equation $\left(k_{i j}\right)$ Is Presented between Brackets

\begin{tabular}{lllll}
\multicolumn{1}{c}{ \%ARD } & \multicolumn{1}{c}{ SRK } & \multicolumn{1}{c}{ SRK + Joback ${ }^{a}$} & \multicolumn{1}{c}{ PR } & \multicolumn{1}{c}{ PR + Joback } \\
$\mathrm{CO}_{2}+$ linalool & $2.495(0.080)$ & $2.672(0.083)$ & $2.627(0.090)$ & $2.690(0.081)$ \\
$\mathrm{CO}_{2}+$ limonene & $2.815(0.081)$ & $b$ & $2.484(0.089)$ & $b$ \\
$\mathrm{CO}_{2}+$ linalool + limonene & $9.023(0.307)$ & $9.044(0.290)$ & $13.120(0.059)$ & $13.273(0.059)$
\end{tabular}

${ }^{a_{T}}$ The linalool critical properties used were the ones obtained using the GC method Joback-methodology I. For limonene, the CPs obtained through methodology II were used. ${ }^{b}$ Joback-GC method cannot be applied to limonene. 
However, density predictions show problems at low temperatures. In the second part of this work, experimental densities and vapor pressures were used to estimate the critical properties and the acentric factor directly by the SoaveRedlich-Kwong and Peng-Robinson EoSs. The two equations show similar correlation ability for densities and vapor pressures: SRK EoS presents a global \%ARD of 3.16 and 0.62 for vapor pressure and density, respectively, while for the Peng-Robinson EoS the corresponding values are 3.61 and 0.66. Both EoSs give critical property estimates closer to those calculated by the Joback method, which is the preferred for this type of compounds. The usefulness of the estimated pure compound properties has been validated through the description of low-pressure VLE data in binary terpene mixtures and solubility data of supercritical $\mathrm{CO}_{2}$ in limonene and/or linalool.

\section{ASSOCIATED CONTENT}

\section{S Supporting Information}

The Supporting Information is available free of charge on the ACS Publications website at DOI: 10.1021/acs.iecr.7b02247.

Joback, Constantinou and Gani and Wilson-Jasperson critical temperature and pressure contributions; density (this work) and vapor pressure (literature) of pure terpenes and terpenoids at different temperatures; average relative deviation between the experimental and the predicted densities and vapor pressures, calculated using the PR and SRK EoSs, with critical properties estimated by the GC methods, and using the SRK and PR EoSs; comparison between the experimental and calculated densities and vapor pressures by the two different approaches using in this work (PDF)

\section{AUTHOR INFORMATION}

\section{Corresponding Author}

*Tel.: +351 273303086. Fax: +351 273313051. E-mail: spinho@ipb.pt.

\section{ORCID (ㅇ)}

Mónia A. R. Martins: 0000-0003-0748-1612

Pedro J. Carvalho: 0000-0002-1943-0006

André M. Palma: 0000-0002-5580-6883

Urszula Domańska: 0000-0001-5034-5873

João A. P. Coutinho: 0000-0002-3841-743X

Simão P. Pinho: 0000-0002-9211-857X

\section{Notes}

The authors declare no competing financial interest.

\section{ACKNOWLEDGMENTS}

This work was developed in the scope of the projects POCI-010145-FEDER-007679-CICECO-Aveiro Institute of Materials (ref. FCT UID/CTM/50011/2013), POCI-01-0145-FEDER006984-Associate Laboratory LSRE-LCM both funded by European Regional Development Fund (ERDF) through COMPETE2020, Programa Operacional Competitividade e Internacionalização (POCI), and by national funds through FCT (Fundação para a Ciência e a Tecnologia). This work is also a result of project “AIProcMat@N2020 (Advanced Industrial Processes and Materials for a Sustainable Northern Region of Portugal 2020)", with the reference NORTE-010145-FEDER-000006, supported by Norte Portugal Regional Operational Programme (NORTE 2020), under the Portugal
2020 Partnership Agreement, through ERDF. M.A.R.M. acknowledges FCT for her Ph.D. grant (SFRH/BD/87084/ 2012) and COST for the STSM Grant from COST action CM1206. P. J. Carvalho also acknowledges FCT for a contract under the Investigador FCT 2015, Contract No. IF/00758/ 2015. A.M.P. acknowledges Infochem-KBC for his Ph.D. grant. The software Multiflash from Infochem-KBC was applied in some of the calculations

\section{REFERENCES}

(1) Zwenger, S.; Basu, C. Plant Terpenoids: Applications and Future Potentials. Biotechnol. Mol. Biol. Rev. 2008, 3 (1), 1.

(2) Schwab, W.; Fuchs, C.; Huang, F.-C. Transformation of Terpenes into Fine Chemicals. Eur. J. Lipid Sci. Technol. 2013, 115 (1), 3.

(3) Caputi, L.; Aprea, E. Use of Terpenoids as Natural Flavouring Compounds in Food Industry. Recent Patents Food, Nutr. Agric. 2011, 3 (1), 9.

(4) Yoo, K.-Y.; Park, S.-Y. Terpenoids as Potential Anti-Alzheimer's Disease Therapeutics. Molecules 2012, 17 (3), 3524.

(5) Mateo, J. J.; Jiménez, M. Monoterpenes in Grape Juice and Wines. J. Chromatogr. A 2000, 881 (1-2), 557.

(6) Chen, W.; Viljoen, A. M. Geraniol - A Review of a Commercially Important Fragrance Material. S. Afr. J. Bot. 2010, 76 (4), 643.

(7) Guenther, A.; Karl, T.; Harley, P.; Wiedinmyer, C.; Palmer, P. I.; Geron, C. Estimates of Global Terrestrial Isoprene Emissions Using MEGAN (Model of Emissions of Gases and Aerosols from Nature). Atmos. Chem. Phys. 2006, 6 (11), 3181.

(8) Yan, X.; Dong, Q.; Hong, X. Reliability Analysis of GroupContribution Methods in Predicting Critical Temperatures of Organic Compounds. J. Chem. Eng. Data 2003, 48 (2), 374.

(9) Joback, S. M. A Unified Approach to Physical Property Estimation Using Multivariate Statistical Techniques. Ph.D. Dissertation, Massachusetts Institute of Technology, Cambridge, MA, 1984

(10) Ambrose, D. Correlation and Estimation of Vapor-Liquid Critical Properties. I. Critical Temperatures of Organic Compounds; National Physical Laboratory, 1978; Vol. 92.

(11) Constantinou, L.; Gani, R. New Group Contribution Method for Estimating Properties of Pure Compounds. AIChE J. 1994, 40 (10), 1697.

(12) Valderrama, J. O.; Forero, L. A.; Rojas, R. E. Extension of a Group Contribution Method To Estimate the Critical Properties of Ionic Liquids of High Molecular Mass. Ind. Eng. Chem. Res. 2015, 54 (13), 3480.

(13) Valderrama, J. O.; Robles, P. A. Critical Properties, Normal Boiling Temperatures, and Acentric Factors of Fifty Ionic Liquids. Ind. Eng. Chem. Res. 2007, 46 (4), 1338.

(14) Smith, J. R. L.; Negishi, E.; Arai, K.; Saito, S. Measurement of Critical Temperatures of Terpenes. J. Chem. Eng. Jpn. 1990, 23 (1), 99.

(15) Tsonopoulos, C.; Ambrose, D. Vapor-Liquid Critical Properties of Elements and Compounds. 6. Unsaturated Aliphatic Hydrocarbons. J. Chem. Eng. Data 1996, 41 (4), 645.

(16) Poling, B. E.; Prausnitz, J. M.; O’Connell, J. P. The Properties of Gases and Liquids, 4th ed.; McGraw-Hill, 1987.

(17) Poling, B. E.; Prausnitz, J. M.; O’Connell, J. P. The Properties of Gases and Liquids, 5th ed.; McGraw-Hill: New York, 2001.

(18) Martins, M. A. R.; Domańska, U.; Schröder, B.; Coutinho, J. A. P.; Pinho, S. P. Selection of Ionic Liquids to Be Used as Separation Agents for Terpenes and Terpenoids. ACS Sustainable Chem. Eng. 2016, 4 (2), 548.

(19) Sanchez-Vicente, Y.; Cabanas, A.; Renuncio, J. A. R.; Pando, C. Supercritical $\mathrm{CO} 2$ as a Green Solvent for Eucalyptus and Citrus Essential Oils Processing: Role of Thermal Effects upon Mixing. RSC Adv. 2013, 3 (17), 6065.

(20) García-Abarrio, S. M.; Torcal, M.; Haya, M. L.; Urieta, J. S.; Mainar, A. M. Thermophysical Properties of $\{( \pm)$-Linalool + Propan- 
1-Ol\}: A First Stage towards the Development of a Green Process. J. Chem. Thermodyn. 2011, 43 (4), 527.

(21) Riedel, L. Estimation of Unknown Critical Pressures of Organic Compounds. Z. Elektrochem. 1949, 53, 222.

(22) Lyderren, A. L. Estimation of Critical Properties of Organic Compounds by the Method of Group Contributions. Engineering Experiment Station Report 3; College of Engineering, University of Wisconsin: Madison, WI, 1955.

(23) Wilson, M.; Jasperson, L. V. Cited by Poling et al. Critical Constants Tc and Pc Estimation Based on Zero, First, and Second Order Methods. Paper Presented at the AIChE Meeting, New Orleans, Louisiana, 1996.

(24) Marrero-Morejón, J.; Pardillo-Fontdevila, E. Estimation of Pure Compound Properties Using Group-Interaction Contributions. AIChE J. 1999, 45 (3), 615.

(25) Ambrose, D. Correlation and Estimation of Vapor-Liquid Critical Properties. II. Critical Pressures and Volumes of Organic Compounds. Natl. Phys. Lab. NPL Rep. Chem. 1979, 98.

(26) Daubert, T. E. State-of-the-Art-Property Predictions. Hydrocarb. Process. 1980, 107.

(27) Fedors, R. F. A Relationship between Chemical Structure and the Critical Temperature. Chem. Eng. Commun. 1982, 16 (1-6), 149.

(28) Klincewicz, K. M.; Reid, R. C. Estimation of Critical Properties with Group Contribution Methods. AIChE J. 1984, 30 (1), 137.

(29) Joback, K. G.; Reid, R. C. Estimation of Pure-Component Properties from Group-Contributions. Chem. Eng. Commun. 1987, 57 (1-6), 233.

(30) Somayajulu, G. R. Estimation Procedures for Critical Constants. J. Chem. Eng. Data 1989, 34 (1), 106.

(31) Chein-Hsiun, T. Group-Contribution Estimation of Critical Temperature with Only Chemical Structure. Chem. Eng. Sci. 1995, 50 (22), 3515.

(32) Marrero, J.; Gani, R. Group-Contribution Based Estimation of Pure Component Properties. Fluid Phase Equilib. 2001, 183-184, 183.

(33) Wen, X.; Qiang, Y. A New Group Contribution Method for Estimating Critical Properties of Organic Compounds. Ind. Eng. Chem. Res. 2001, 40 (26), 6245.

(34) Spencer, C. F.; Daubert, T. E.; Danner, R. P. A Critical Review of Correlations for the Critical Properties of Defined Mixtures. AIChE J. 1973, 19 (3), 522.

(35) Lee, B. I.; Kesler, M. G. A Generalized Thermodynamic Correlation Based on Three-Parameter Corresponding States. AIChE J. 1975, 21 (3), 510.

(36) van der Waals, J. D. On the Continuity of the Gaseous and Liquid States. Ph.D. Dissertation, Universiteit Leiden, 1873.

(37) Redlich, O.; Kwong, J. N. S. On the Thermodynamics of Solutions. V. An Equation of State. Fugacities of Gaseous Solutions. Chem. Rev. 1949, 44 (1), 233.

(38) Soave, G. Equilibrium Constants from a Modified RedlichKwong Equation of State. Chem. Eng. Sci. 1972, 27 (6), 1197.

(39) Peng, D.-Y.; Robinson, D. B. A New Two-Constant Equation of State. Ind. Eng. Chem. Fundam. 1976, 15 (1), 59.

(40) Chaves, I. D. G.; López, J. R. G.; Zapata, J. L. G.; Robayo, A. L.; Niño, G. R. Process Simulation in Chemical Engineering. In Process Analysis and Simulation in Chemical Engineering; Springer International Publishing: Cham, 2016; pp 1-51.

(41) Yaws, C. L. Thermophysical Properties of Chemicals and Hydrocarbons; William Andrew, 2008.

(42) Domańska, U.; Papis, P.; Szydłowski, J.; Królikowska, M.; Królikowski, M. Excess Enthalpies of Mixing, Effect of Temperature and Composition on the Density, and Viscosity and Thermodynamic Properties of Binary Systems of \{Ammonium-Based Ionic Liquid + Alkanediol\}. J. Phys. Chem. B 2014, 118 (44), 12692.

(43) Kenyon, J.; Pickard, R. H. VII.-Investigations on the Dependence of Rotatory Power on Chemical Constitution. Part XI. The Co-Ordination of the Rotatory Powers (a) of Menthyl Compounds, (B) of the Menthones, and (c) of the Borneols. J. Chem. Soc., Trans. 1915, 107, 35.
(44) Müller, A. Die Parachore, Viskositäten Und Chelatringbildung Der Alkohole. Fette Seifen 1942, 49 (8), 572.

(45) Martínez-López, J. F.; Mainar, A. M.; Urieta, J. S.; Pardo, J. I. Thermophysical Properties of $\{$ R-Fenchone + Ethanol $\}$ at Several Temperatures and Pressures. J. Chem. Thermodyn. 2014, 69, 48.

(46) Atik, Z.; Ewing, M. B.; McGlashan, M. L. Chiral Discrimination in Liquids. Excess Molar Volumes of $(1-\mathrm{x}) \mathrm{A}++\mathrm{xA}-$, Where A Denotes Limonene, Fenchone, and.alpha.-Methylbenzylamine. J. Phys. Chem. 1981, 85 (22), 3300.

(47) Liu, H.; Kido, S.; Kamiyama, T.; Fujisawa, M.; Kimura, T. Thermodynamic Properties of Chiral Fenchones in Some Solutions at $\mathrm{T}=298.15 \mathrm{~K}$. J. Chem. Thermodyn. 2011, 43 (4), 627.

(48) Florido, P. M.; Andrade, I. M. G.; Capellini, M. C.; Carvalho, F. H.; Aracava, K. K.; Koshima, C. C.; Rodrigues, C. E. C.; Gonçalves, C. $B$. Viscosities and Densities of Systems Involved in the Deterpenation of Essential Oils by Liquid-Liquid Extraction: New UNIFAC-VISCO Parameters. J. Chem. Thermodyn. 2014, 72, 152.

(49) Arce, A.; Marchiaro, A.; Soto, A. Liquid-liquid Equilibria of Linalool + Ethanol + Water, Water + Ethanol + Limonene, and Limonene + Linalool + Water Systems. J. Solution Chem. 2004, 33 (5), 561.

(50) Comelli, F.; Francesconi, R.; Castellari, C. Densities, Viscosities, and Excess Molar Enthalpies of Binary Mixtures Containing Essential Oils at (298.15 and 313.15) K. The (S)-(-)-Limonene + Cineole, (S)(-)-Limonene + Linalool, and Cineole + Linalool Systems. J. Chem. Eng. Data 2001, 46 (4), 868.

(51) Clará, R. A.; Marigliano, A. C. G. G.; Sólimo, H. N. Density, Viscosity, and Refractive Index in the Range (283.15 to 353.15$) \mathrm{K}$ and Vapor Pressure of $\alpha$-Pinene, D-Limonene, $( \pm)$-Linalool, and Citral Over the Pressure Range 1.0 kPa Atmospheric Pressure. J. Chem. Eng. Data 2009, 54 (3), 1087.

(52) Torcal, M.; Teruel, M. I.; García, J.; Urieta, J. S.; Mainar, A. M. $\mathrm{P} \rho \mathrm{T}$ Measurements of the (Ethanol + Linalool), (Propan-1-Ol + Linalool), and (Propan-2-Ol + Linalool) Mixtures: Cubic and Statistical Associating Fluid Theory-Based Equation of State Analyses. J. Chem. Eng. Data 2010, 55 (11), 5332.

(53) Lepori, L.; Mengheri, M.; Mollica, V. Discriminating Interactions between Chiral Molecules in the Liquid Phase: Effect on Volumetric Properties. J. Phys. Chem. 1983, 87 (18), 3520.

(54) Barata, P. A.; Serrano, M. L. Densities and Viscosities of Thymol + 1,8-Cineole. J. Chem. Eng. Data 1994, 39 (2), 298.

(55) Alfaro, P.; Langa, E.; Martínez-López, J. F.; Urieta, J. S.; Mainar, A. M. Thermophysical Properties of the Binary Mixtures (1,8-Cineole +1 -Alkanol $)$ at $\mathrm{T}=(298.15$ and 313.15$) \mathrm{K}$ and at Atmospheric Pressure. J. Chem. Thermodyn. 2010, 42 (2), 291.

(56) Torcal, M.; García-Abarrio, S.; Pardo, J. I.; Mainar, A. M.; Urieta, J. S. P, P, T Measurements and Isobaric Vapor-LiquidEquilibria of the 1,3,3-Trimethyl-2-oxabicycle[2,2,2] octane + Propan1-Ol Mixture: Cubic and Statistical Associating Fluid Theory-Based Equation of State Analysis. J. Chem. Eng. Data 2010, 55 (12), 5932.

(57) Lasarte, J. M.; Martín, L.; Langa, E.; Urieta, J. S.; Mainar, A. M. Setup and Validation of a $\mathrm{P} \rho \mathrm{T}$ Measuring Device. Volumetric Behavior of the Mixture 1,8-Cineole + Ethanol. J. Chem. Eng. Data 2008, 53 (6), 1393.

(58) Comelli, F.; Ottani, S.; Francesconi, R.; Castellari, C. Densities, Viscosities, and Refractive Indices of Binary Mixtures Containing NHexane + Components of Pine Resins and Essential Oils at 298.15 K. J. Chem. Eng. Data 2002, 47 (1), 93.

(59) Tavares Sousa, A.; Nieto de Castro, C. A. Density of $\alpha$-Pinene, B-Pinene, Limonene, and Essence of Turpentine. Int. J. Thermophys. 1992, 13 (2), 295.

(60) Ribeiro, A.; Bernardo-Gil, G. Densities and Refractive Indices of Components of Pine Resin. J. Chem. Eng. Data 1990, 35 (2), 204.

(61) Cunha, D. L.; Coutinho, J. A. P.; Daridon, J. L.; Reis, R. A.; Paredes, M. L. L. Experimental Densities and Speeds of Sound of Substituted Phenols and Their Modeling with the Prigogine-FloryPatterson Model. J. Chem. Eng. Data 2013, 58 (11), 2925.

(62) Cheng, K.-W.; Kuo, S.-J.; Tang, M.; Chen, Y.-P. Vapor-liquid Equilibria at Elevated Pressures of Binary Mixtures of Carbon Dioxide 
with Methyl Salicylate, Eugenol, and Diethyl Phthalate. J. Supercrit. Fluids 2000, 18 (2), 87.

(63) do Carmo, F. R.; Evangelista, N. S.; Fernandes, F. A. N.; de Sant'Ana, H. B. Evaluation of Optimal Methods for Critical Properties and Acentric Factor of Biodiesel Compounds with Their Application on Soave-Redlich-Kwong and Peng-Robinson Equations of State. J. Chem. Eng. Data 2015, 60 (11), 3358.

(64) Jaubert, J.-N.; Privat, R.; Le Guennec, Y.; Coniglio, L. Note on the Properties Altered by Application of a Péneloux-type Volume Translation to an Equation of State. Fluid Phase Equilib. 2016, 419, 88.

(65) Le Guennec, Y.; Privat, R.; Jaubert, J.-N. Development of the Translated-Consistent Tc-PR and Tc-RK Cubic Equations of State for a Safe and Accurate Prediction of Volumetric, Energetic and Saturation Properties of Pure Compounds in the Sub- and Super-Critical Domains. Fluid Phase Equilib. 2016, 429, 301.

(66) Yaws, Carl L. Yaws' Critical Property Data for Chemical Engineers and Chemists; Knovel, 2014; http://app.knovel.com/hotlink/toc/ id:kpYCPDCECD/yaws-Critical-Property/yaws-Critical-Property.

(67) Nadais, M. H.; Bernardo-Gil, M. G. Vapour - Liquid Equilibria of $\alpha$-Pinene + Limonene at Reduced Pressures. Fluid Phase Equilib. 1993, 91 (2), 321.

(68) Melo, S. A. B. V. de; Pallado, P.; Guarise, G. B.; Bertucco, A. High-Pressure Vapor-Liquid Equilibrium Data for Binary and Ternary Systems Formed by Supercritical CO2, Limonene and Linalool. Braz. J. Chem. Eng. 1999, 16 (1), 7. 